The research program of the Center for Economic Studies (CES) produces a wide range of theoretical and empirical economic analyses that serve to improve the statistical programs of the U.S. Bureau of the Census. Many of these analyses take the form of CES research papers. The papers are intended to make the results of CES research available to economists and other interested parties in order to encourage discussion and obtain suggestions for revision before publication. The papers are unofficial and have not undergone the review accorded official Census Bureau publications. The opinions and conclusions expressed in the papers are those of the authors and do not necessarily represent those of the U.S. Bureau of the Census. Republication in whole or part must be cleared with the authors.

\title{
THE SURVIVAL OF INDUSTRIAL PLANTS
}

by

\section{Michael Gort \\ SUNY at Buffalo}

J. Bradford Jensen

U.S. Bureau of the Census

and

Seong-Hoon Lee

SUNY at Buffalo

\section{CES 02-25 October, 2002}

\footnotetext{
All papers are screened to ensure that they do not disclose confidential information. Persons who wish to obtain a copy of the paper, submit comments about the paper, or obtain general information about the series should contact Sang V. Nguyen, Editor, Discussion Papers, Center for Economic Studies, Washington Plaza II, Room 206, $\overline{\text { Bureau }}$ of the Census, Washington, D.C. 20233-6300, (301-457-1882) or INTERNET address snguyendces.census.gov.
} 


\begin{abstract}
The study seeks to explain the attrition rate of new manufacturing plants in the United States in terms of three vectors of variables. The first explains how survival of the fittest proceeds through learning by firms (plants) about their own relative efficiency. The second explains how efficiency systematically changes over time and what augments or diminishes it. The third captures the opportunity cost of resources employed in a plant. The model is tested using maximum-likelihood probit analysis with very large samples for successive census years in the 1967-97 period. One sample consists of an unbalanced panel of about three-fourths of a million plants of single and multi-unit firms, or alternatively of about 300,000 plants if only the most reliable data are considered. The second is restricted to the plants of multi-unit firms in the same time span and consists of an unbalanced panel of more than 100,000 plants. The empirical analysis strongly confirms the predictions of the model.
\end{abstract}

Key Words: Plant Survival, Efficiency, Learning-by-doing, Technical Change.

JEL Classification: 030, L20. 
It is now well known that the economic life of most new firms is far shorter than the life usually attributed to their tangible assets. A number of studies, both for the United States and for other countries, show that roughly five to ten percent of the firms in a given market leave that market over the span of a single year. ${ }^{1}$ Since the survival rate for new firms is lower than for older firms (a conclusion demonstrated later), the attrition rate for new firms must be higher still.

Is this rate of attrition a consequence of mergers, reorganizations and transfers of assets to other firms rather than the abandonment of assets? An examination of the record on plant survival casts some light on this question. Plant transfers to new owners are not classified in the U.S. economic censuses as new plants. Therefore, the disappearance of plants between successive census years gives us at least a partial indication of asset abandonments, even though some components of abandoned plants may be put to other uses.

Table 1 shows the survival ratios for cohorts of new U.S. manufacturing plants in successive census years (that is, at five-year intervals). These ratios have been remarkably stable over the $1972-97$ period. Roughly half of new plants disappear over the five-year interval following entry, and two-thirds in a ten-year span. Within twenty years, fewer than one-fifth remain. Even if one excludes very small plants for which information is derived from administrative records rather than from census responses, the percentage surviving rises only slightly by several percentage points even though sample size is reduced by almost 60 percent.

\footnotetext{
1 This range is consistent with the results shown for the United States in Dunne, Roberts and Samuelson (1988), for Canada in Baldwin and Gorecki (1991) and for Germany in Schwalbach (1991).
} 
Table 1:

Survival Ratios for Cohorts of New U.S. Manufacturing Plants, 1967-1997*

\begin{tabular}{|c|c|c|c|c|c|c|c|c|c|c|c|c|c|c|}
\hline \multirow{3}{*}{$\begin{array}{l}\text { Entry } \\
\text { Year }\end{array}$} & \multicolumn{14}{|c|}{ Survival Ratio for } \\
\hline & \multicolumn{7}{|c|}{ All } & \multicolumn{7}{|c|}{ Without Administrative Record Cases } \\
\hline & $\begin{array}{l}\text { No. of } \\
\text { New } \\
\text { Plants } \\
\end{array}$ & 1972 & 1977 & 1982 & 1987 & 1992 & 1997 & $\begin{array}{l}\text { No. of } \\
\text { New } \\
\text { Plants }\end{array}$ & 1972 & 1977 & 1982 & 1987 & 1992 & 1997 \\
\hline 1967 & 97,285 & $\begin{array}{c}0.52 \\
(0.52)\end{array}$ & $\begin{array}{c}0.36 \\
(0.69)\end{array}$ & $\begin{array}{c}0.25 \\
(0.69)\end{array}$ & $\begin{array}{c}0.19 \\
(0.76)\end{array}$ & $\begin{array}{c}0.14 \\
(0.74)\end{array}$ & $\begin{array}{c}0.11 \\
(0.79)\end{array}$ & 42,246 & $\begin{array}{c}0.52 \\
(0.52)\end{array}$ & $\begin{array}{c}0.39 \\
(0.75)\end{array}$ & $\begin{array}{c}0.31 \\
(0.79)\end{array}$ & $\begin{array}{c}0.24 \\
(0.77)\end{array}$ & $\begin{array}{c}0.19 \\
(0.79)\end{array}$ & $\begin{array}{c}0.15 \\
(0.79)\end{array}$ \\
\hline 1972 & 119,250 & 1.00 & $\begin{array}{c}0.54 \\
(0.54)\end{array}$ & $\begin{array}{c}0.36 \\
(0.67)\end{array}$ & $\begin{array}{c}0.26 \\
(0.72)\end{array}$ & $\begin{array}{c}0.19 \\
(0.73)\end{array}$ & $\begin{array}{c}0.15 \\
(0.79)\end{array}$ & 53,526 & 1.00 & $\begin{array}{c}0.53 \\
(0.53)\end{array}$ & $\begin{array}{c}0.39 \\
(0.74)\end{array}$ & $\begin{array}{c}0.28 \\
(0.72)\end{array}$ & $\begin{array}{c}0.22 \\
(0.79)\end{array}$ & $\begin{array}{c}0.18 \\
(0.82)\end{array}$ \\
\hline 1977 & 145,562 & & 1.00 & $\begin{array}{c}0.49 \\
(0.49)\end{array}$ & $\begin{array}{c}0.32 \\
(0.65)\end{array}$ & $\begin{array}{c}0.23 \\
(0.72)\end{array}$ & $\begin{array}{c}0.17 \\
(0.74)\end{array}$ & 56,897 & & 1.00 & $\begin{array}{c}0.49 \\
(0.49)\end{array}$ & $\begin{array}{c}0.34 \\
(0.69)\end{array}$ & $\begin{array}{c}0.25 \\
(0.74)\end{array}$ & $\begin{array}{c}0.20 \\
(0.80)\end{array}$ \\
\hline 1982 & 130,716 & & & 1.00 & $\begin{array}{c}0.56 \\
(0.56)\end{array}$ & $\begin{array}{c}0.36 \\
(0.64)\end{array}$ & $\begin{array}{c}0.27 \\
(0.75)\end{array}$ & 52,860 & & & 1.00 & $\begin{array}{c}0.49 \\
(0.49)\end{array}$ & $\begin{array}{c}0.34 \\
(0.69)\end{array}$ & $\begin{array}{c}0.27 \\
(0.79)\end{array}$ \\
\hline 1987 & 132,106 & & & & 1.00 & $\begin{array}{c}0.50 \\
(0.50)\end{array}$ & $\begin{array}{c}0.34 \\
(0.68)\end{array}$ & 46,035 & & & & 1.00 & $\begin{array}{c}0.55 \\
(0.55)\end{array}$ & $\begin{array}{c}0.40 \\
(0.73)\end{array}$ \\
\hline 1992 & 143,238 & & & & & 1.00 & $\begin{array}{c}0.53 \\
(0.53)\end{array}$ & 59,872 & & & & & 1.00 & $\begin{array}{c}0.55 \\
(0.55)\end{array}$ \\
\hline
\end{tabular}

* Entry year is the census year in which each plant's record first appears while the survival ratio designates the ratio for each cohort of the number of plants operating in successive census years to number of plants in the first year of the cohort. Ratios in parentheses are survival ratios relative to the number surviving in the preceding year. 
To be sure, a large proportion of these new plants are quite small. Nevertheless, in the aggregate a substantial quantity of assets are periodically abandoned and this warrants considerable attention to the question of who does and who does not survive. ${ }^{2}$ For example, plants surviving less than five years account for slightly more than 20 percent of the initial capital outlays of new plants in their cohort. Those that survive less than ten, and those that survive less than twenty years account, respectively, for more than a third and about half of the initial capital outlays of their cohorts.

We start by specifying a model of plant survival. This discussion is divided into three subsections. In subsection I.a, we assume a normal distribution of plant efficiencies but one in which each plant does not know, at the outset, its relative efficiency. We then examine the effects of survival of the fittest on the average duration of survival and on the relation of probability of survival to size of plant. This part of the analysis leans heavily on Jovanovic (1982). In I.b, we consider the factors that lead to changes in the initial endowments of plants and hence their relative efficiencies. In particular, we examine the contribution (i) of learning-by-doing and new investment, (ii) of technological change and its impact on the obsolescence of endowments and (iii) of variations in a plant's ability to adapt to technical change. This is an extension of the Agarwal and Gort (2002) approach. In I.c, we consider the opportunity cost of inputs as it affects decisions to withdraw from a market. As a departure from some earlier studies, we seek to identify systematic variations across plants in the opportunity cost of inputs.

\footnotetext{
${ }^{2}$ An interesting side issue is whether conventional depreciation accounts, whether for tax purposes or for estimating net capital stocks, are not subject to a selection bias. That is, are estimates of economic lives drawn from the records of surviving plants relevant for the universe of plants? What, one may argue, is the
} 


\section{A Model of Survival}

I.a. Selection of the fittest

Assume that a plant draws a random productivity $\theta$ from a prior probability distribution with a cumulative distribution function $\operatorname{Pr} o b\{\theta \leq B\}=F(B)$, with $F(0)=0$ and $F(B)=1$ for $B<\infty$. We assume that $\theta$ is normally distributed with mean $\mu_{\theta}$ and variance $\sigma_{\theta}{ }^{2}$. An entrant does not know his own $\theta$, but observes only $\lambda=\theta+\varepsilon$ where $\varepsilon$ is independently drawn from a normal distribution with mean 0 and variance $\sigma_{\varepsilon}{ }^{2}$. Thus an entrant into an industry has, initially, only a noisy observation on $\theta$. As production proceeds, the plant learns with increasing accuracy in successive periods the true value of $\theta$. That is, incumbents of age $a$ observe $\lambda_{a}=\theta+\varepsilon_{a}$ and on this basis make inferences about $\theta$. It can be shown that the change in the posterior variance of $\theta$ is:

$$
\Delta \sigma_{a}{ }^{2}=-\frac{\sigma_{a-1}{ }^{4}}{{\sigma_{a-1}}^{2}+\sigma_{\varepsilon}{ }^{2}}<0
$$

where $\Delta \sigma_{a}{ }^{2}=\sigma_{a}{ }^{2}-\sigma_{a-1}{ }^{2}$. Thus, the accuracy of predicted values of $\theta$ increases at a decreasing rate $\left(\Delta \sigma_{a}{ }^{2}-\Delta \sigma_{a-1}{ }^{2}>0\right)$.

Accordingly, a plant of age $a$ decides in each period whether to stay in the industry or exit it, given the best estimates of $\theta$ :

$$
\eta_{a}=E\left[\theta \mid \theta+\varepsilon_{1}, \theta+\varepsilon_{2}, \ldots, \theta+\varepsilon_{a}\right]
$$

Let $\phi>0$ be the opportunity cost of the plant's inputs if used in the best alternative activity. For some inputs, it is simply the plant's escapable cost or market

relevance of potential life for structures of say 40 years if the true economic life of the plant is less than 10 years? 
price of the inputs. Let $\bar{\eta}_{a}=\gamma(\phi, a)$ be the level of $\eta_{a}$ where the incumbent of age $a$ is indifferent between staying in the industry and exiting it. Then, the incumbent stays in the industry if $\eta_{a} \geq \gamma(\phi, a)$ and exits it if $\eta_{a} \leq \gamma(\phi, a)$.

Plants enter with imperfect information about their own efficiency, and learn progressively as they produce. Such learning leads to the exit of plants with low efficiency with the result that $\bar{\eta}_{a}$ steadily rises as plants age. The least efficient plants drop out first and the variance in efficiency within an entry cohort, therefore, declines as plants age. As a result, the positive effect of a plant's age on plant survival through the selection process continues but at a decreasing rate.

As shown by Gort and Lee (2001), a plant's investment does not end with its initial construction but rather continues over its entire life. The higher the perceived efficiency of the plant, the greater will outlays on the plant be either at the outset or subsequent to its initial construction. That is, experience leads to increased confidence in the success of the venture, and justifies a larger commitment of inputs. The process of noisy selection, accordingly, plays a role not only in affecting survival but also the growth and size of plants. Hence the higher the perceived efficiency of the plant, the greater is both its size and its probability of survival, quite independently of scale economies. ${ }^{3}$ This means that the positive relation between size and survival may not derive from the presence of economies of scale at all.

\section{I.b. Changes in Endowments}

\footnotetext{
3 Among studies that have dealt with the relation of survival and growth or size are Evans (1987a, 1987b), Audretsch (1995), Doms, Dunne and Roberts (1995), Dunne, Roberts and Samuelson (1989) for studies on the U.S., Wagner (1994) on Germany and Mata, Portugal and Guimaraes (1995) on Portugal.
} 
The relative efficiency of plants changes with learning-by-doing and with new investment in endowments. We assume that endowments evolve consistently with a random difference equation. Let $\theta_{a}=A\left(a, T_{i}\right) f\left(K_{a}\right)$ be the function that defines the relative efficiency of plants in industry $i$ at age $a$, where $A$ denotes learning-by-doing as an increasing function of plant age $a$ and technical change $T_{i}$, and $f\left(K_{a}\right)$ denotes an increasing function of endowments $K_{a}$. Learning-by-doing increases the relative efficiency of plants. However, because knowledge available to be learned is finite for a given technology, learning-by-doing increases efficiency, and hence the probability of plant survival, at a decreasing rate.

Plants of age $a$ choose their own investment levels to maximize their expected present discounted value of net revenue. For simplicity, let $c_{a}=I_{a+1}{ }^{2} / 2$ be the cost function of investment in existing endowments, where $I$ denotes the amount of investment. This assumes that the cost function of adding to existing endowments is an increasing and convex function of investment.

For the accumulation of endowments, it is assumed that endowments obsolesce and the rate of obsolescence is a function of the rate of technical change. The higher the technical change, the less adaptable will existing endowments be to the required new investment. Thus the rate of obsolescence is an increasing function of the rate of technical change. Let $q\left(T_{i}\right)$ with $\partial q\left(T_{i}\right) / \partial T_{i}>0$ be the rate of obsolescence where $T_{i}$ is the technology index specific to industry $i$. Then, the accumulation of endowments of a plant in industry $i$ at age $a$ evolves as follows:

$$
K_{a+1}=\left[1-q\left(T_{i}\right)\right] K_{a}+I_{a+1}+v_{a+1},
$$


where $I$ is the new investment of the plant and $\left\{v_{a}\right\}$ is a sequence of independent random shocks. At age $a, K_{a}$ is known, but $K_{a+j}$ for $j \geq 1$ is not known because the effects of $v_{a+1}$ are realized only after the investment decision has been made.

At any age $a$, an incumbent plant must make a decision to stay or to exit. If it stays, it chooses the requisite investment and the dynamic programming problem satisfies

$$
V(K ; A)=\max \left\{V^{S}(K ; A), V^{E}(K ; A)\right\},
$$

where $V^{S}(K ; A)$ denotes a value function for staying in the industry and $V^{E}(K ; A)$ denotes a value function for exiting it. For a decision to exit, the dynamic programming problem is

$$
V^{E}(K ; A)=\max \left\{A\left(a, T_{i}\right) f(K)+\beta \phi\right\},
$$

where $0<\beta<1$ is a discount factor, and for a decision to stay, it is

$$
V^{S}(K ; A)=\max _{I^{\prime}}\left\{A\left(a, T_{i}\right) f(K)-I^{\prime 2} / 2+\beta \int V\left(K^{\prime} ; A^{\prime}\right) d G\left(K^{\prime} \mid K, I, v^{\prime}\right)\right\}
$$

where $G\left(K^{\prime} \mid K, I, v^{\prime}\right)$ is the probability that $K_{t+1} \leq K^{\prime}$, given that $K_{t}=K$ and given the incumbent's investment $I$. Optimal additions to existing endowments are chosen such that current marginal costs equal the marginal expected present value of endowments in the next period as given by

$$
I_{a+1}=I\left(A\left(a, T_{i}\right), q\left(T_{i}\right), K_{a}, v_{a+1}\right) .
$$

The optimal new investment decreases with plant age, given any initial level of endowments. New investment depends on the preceding period's endowments and hence, is an increasing function of the plant's initial endowments. Thus, assuming that new investment is greater than the obsolescence of old endowments, i.e., $I_{a+1}>q\left(T_{i}\right) K_{a}$, the 
plant's endowments increase with plant age, and vice versa. As investment decreases with plant age, the plant's endowments rise at a decreasing rate. However, as plants age, the average endowments of incumbent plants may rise additionally because inefficient plants with low endowments exit while efficient plants with larger endowments remain.

Endowments are, of course, not limited to fixed assets. They include investment in research and development, in the acquisition of managerial skills, and in all forms of what may be called organizational capital. Technical change renders both human and physical inputs obsolete. The higher the rate of technical change, the less relevant are the sunk costs and past experience of incumbents to future output, and the lower the expected survival rate of incumbents.

Finally, plants that employ more human capital are likely to be more adaptable to technical change than plants with low inputs of human capital. For this reason, their survival rate should be higher. Moreover, more productive plants can outbid less productive ones for superior labor and the latter, in turn, should contribute to the productivity and survival of plants.

\section{1.c Opportunity Cost}

The decision to remain or to exit from further production was shown to depend partly on the opportunity cost of a plant's inputs. For some inputs, for example for most labor, opportunity cost is simply the market price of the input (that is, the escapable labor cost of the plant). For other inputs, however, the market price is far below the net present value of all future marginal products of the inputs when used within the firm. This is because some inputs, for example the plant's structure, are completely immobile. Others, 
such as the organizational capital of the firm, are firm-specific and hence not transferable outside the firm. How, for example, does one transfer information about which employee within the firm is best suited for what task? And still other inputs, for example managerial time, can be partially reallocated across plants within a firm but not outside the firm.

It follows, therefore, that the higher the mobility of the inputs of the plant, the higher will be its opportunity cost and the lower the probability of survival for the plant. Thus, a low ratio of fixed capital to other inputs reduces the probability of survival and vice versa. Similarly, a firm with an efficient internal market for its resources - one that permits reallocation of inputs across competing uses within the firm - will be associated with a lower probability of survival for its individual components (plants). Accordingly, on this basis we predict lower survival rates for the plants of multi-unit firms as well as for the plants of firms with diversified outputs. The net effect of diversification, however, is a priori unclear. This is because the "selection effect" arising from an internal market for resources may be offset, or more than offset, by a portfolio effect. That is, a more diversified portfolio of projects reduces risk and, hence, the chance of bankruptcy. The net effect of diversification on survival, given the opposing selection and portfolio effects, can only be determined empirically.

\section{Data and Descriptive Statistics}

Our data are drawn from the U.S. Census Bureau's Longitudinal Research Database (LRD) for manufacturing plants. Because data from the Annual Survey of Manufactures only partially cover the universe of manufacturing plants, the need for 
consistent information on plant survival restricts our data to the Censuses of Manufactures conducted at five-year intervals from 1967 to 1997. We define plants as new the first time they appear in a given census year. The first year for which the birth of a plant could be approximately pinpointed was 1967 and the last new plant cohort for which subsequent survival information was available was 1992 . The resulting sample left us with a non-balanced panel of 768,157 plants. Without plants for which only administrative records were available, the sample was reduced to 311,436 plants.

The previously introduced Table 1 shows the ratios of surviving plants in successive census years to total new plant cohorts. It also shows (in parentheses) the ratios of surviving plants from each cohort to the number in the preceding census year. The ratios of survivors to total new plant cohorts approximate $1 / 2,1 / 3,1 / 4$ and $1 / 5$, respectively, 5, 10, 15 and 20 years after the birth of the cohort.

The following conclusions may be drawn from Table 1. First, as plants age, the fraction surviving steadily decreases. This is consistent with the conclusion of increasing obsolescence of old endowments but continued attrition can also be expected from random shocks. The rate of attrition, however, steadily diminishes. That is the ratio of surviving plants to those in the preceding census year (numbers in parentheses) rises as plants age. Consistent with the model in Section I, the decline in the rate of attrition suggests that surviving plants are of higher efficiency than exiting plants, and/or the distribution of efficiencies is characterized by less variance. The observed pattern shows a high degree of stability across time. The survival ratios, as previously noted, are also only modestly affected if data based on administrative records are excluded. 


\section{Empirical Specification of the Model and Estimates}

\section{III.a. The Empirical Model}

We seek to identify what determines the probability of plant survival. Each incumbent plant faces the choice of continuing to produce or, alternatively, to exit. We have shown that this choice and, hence, the probability of survival for a given population of incumbents depends on three sets of variables. First, there is the accuracy of perception of the plant's own efficiency compared to that of its competitors. The more accurate the perception, the lower is the variance in efficiencies of surviving plants and the higher the subsequent rate of survival. Second, there are the variables that are related to the actual efficiency of plants and to changes in it. Third, there is the opportunity cost of continuing to produce which, as we have indicated, varies systematically across plants.

The accuracy of perceived efficiency rises and, as a consequence, the variance in actual efficiencies declines with the rise in the age of plants as inefficient plants exit. As perceived efficiency rises and errors in estimates narrow, commitments in the form of new investment also rise and plants grow larger. Accordingly, we have identified two predictors of survival: (a) the age of the plant and (b) its size. The relevance of the latter variable, we hypothesize, derives mainly from the effect of success on investment outlays (hence size) rather than from scale economies. In the context of our model, size as a proxy for past success is used as a predictor of future success and, hence, future survival.

An important question is whether the predicted relation between survival and size extends over the entire range of plant sizes or attenuates beyond some size. That is, does the dispersion in efficiencies diminish beyond some scale for surviving plants? The same question can be asked about the relation of survival and age. Our analysis indicates a 
decline in the variance of efficiencies with plant age. This means that increments to age should have a diminishing effect on survival rate since dispersion in relative efficiencies contributes to failure.

The change in the average efficiency of surviving plants as weaker ones exit is reinforced through learning-by-doing. Such learning will again be a function of the age of the plant. However, given a finite stock of knowledge for any technology, there is progressively less to be learned through additional experience. Thus, once again, survival should rise at a decreasing rate with plant age. The initial endowments of plants, both physical and managerial, obsolesce over time and the higher the rate of technical change for a given technology, the faster will be the rate of obsolescence and the lower the survival rate of plants. Technical change is proxied in two ways (see below). The higher the employment of human capital, proxied by average wage, the greater is the probable adaptability of plants to a changing environment and technology and, hence, the higher their survival rate.

The opportunity cost of resources is proxied in two ways. First, the mobility of inputs is inversely related to the ratio of fixed capital to other inputs. A higher ratio should reduce opportunity cost and raise the survival rate. Second, the more efficient the internal market for reallocating managerial and related resources, the higher is the opportunity cost and the lower the survival rate.

Because the dependent variable has a discrete choice value of 0 or 1 by our construction (the plant either does or does not survive), OLS estimation is statistically inefficient. Accordingly, we rely on maximum-likelihood probit estimation. A hazard 
duration model as an alternative would have been inefficient and difficult to interpret with observations five years apart (that is, in census years).

We first test our model with the specification in equation (8).

$$
\begin{aligned}
D_{A}\left(a^{\prime} \mid a\right)=\delta_{0} & +\delta_{1} a+\delta_{2} T_{i}+\delta_{3} \log w+\delta_{4} \log L+\delta_{5}(\log L)^{2} \\
& +\delta_{6} \log k+\delta_{7} M+\delta_{8} S_{i}+u_{A},
\end{aligned}
$$

where $a, T_{i}, w, L, k, M, S_{i}$ and $u_{A}$ denote, respectively, plant age, industry technology index, the quality of human capital employed, plant size, the ratio of fixed capital to other inputs, an index measuring the efficiency of the internal market for resources, industry average survival rate and error term. Additional information on data sources is given below. All right hand variables have been previously discussed with the exception of the industry average survival rate. Industry average survival rate is intended to capture all unidentified attributes associated with the industry that affect survival. These may include the stages of the industry's life cycle to which the data are relevant, the stability or instability of market demand, the relative ease of entry, etc. Previous studies have shown such attributes to be relevant to the exit rate and lack of information on each individually obliged as to use a catchall variable.

The dependent variable is categorical with a value of 0 if plants continue to survive and of 1 if plants fail to survive to the next census year (conditional on survival to the last one). In equation (9), the empirical analysis of the effect of plant age on survival is based on data at five-year intervals (that is, for census years). This is not sufficient to permit us to capture non-linearities in the relation. Accordingly, we next rely on an empirical specification that permits us to examine the different impacts of learning-by- 
doing across age cohorts. This is done via the introduction of the fixed effects of age cohorts in place of a single plant age variable.

We then test the following specification with the fixed effect of age cohorts:

$$
\begin{aligned}
D_{A f}\left(a^{\prime} \mid a\right)=\delta_{0} & +\Sigma_{j=2}^{5} \delta_{1 j} a_{j}+\delta_{2} T_{i}+\delta_{3} \log w+\delta_{4} \log L+\delta_{5}(\log L)^{2} \\
& +\delta_{6} \log k+\delta_{7} M+\delta_{8} S_{i}+u_{A f}
\end{aligned}
$$

where $a_{j}$ (for $\left.j=2,3,4,5\right)$ indicate fixed age effects where $a_{j}$ is categorical with a value of 1 if a plant operates for $j$ census years and of 0 otherwise, and the remaining variables are as defined for equation (8). The coefficients of $\delta_{1 j}$, for $j=2,3,4,5$, measure the independent survival effects associated with each age cohort. Because the dummy for $a_{1}$ is used as a baseline and dropped in the equation, each $\delta_{1 j}$ captures the proportional changes in plant survival of each age cohort relative to the first age cohort.

The probabilities of any given plant staying in the industry with a single plant age variable, i.e., $\operatorname{Pr}\left(D_{A}\left(a^{\prime} \mid a\right)=0\right)$, and with fixed age effects, i.e., $\operatorname{Pr}\left(D_{A f}\left(a^{\prime} \mid a\right)=0\right)$, are both tested with maximum-likelihood probit estimation.

III.b. Measurement of the variables

For equations (8) and (9), the variables that are most difficult to proxy are the rate of technical change and the efficiency of the internal market for resource reallocation. For this reason, technical change was proxied by two alternative indexes, one representing an attempt to capture the technology intensiveness of the primary industry of the plant and, the other, the rate of innovation in the industry. The two indexes, Tech1 and Tech2, are both categorical with a value of 2 for high technology and of 1 for low technology. Both 
are industry indexes with classification of high and low technology for the Tech1 variable based on 3-digit SIC data on the proportion of total employment in R\&D, as shown in Hadlock, Hecker and Gannon (1991). The classification of high and low technology for the Tech2 variable is based on 4-digit SIC data on the number of innovations, as shown in Edwards and Gordon (1984). Tech2 is categorical with a value of 2 if the number of innovations in each 4-digit industry is equal to or larger than the average number of innovations in all industries, and a value of 1 otherwise.

Efficiency of the internal market was measured for the entire sample by whether the firm had only one or more than one plant (with a categorical value of 0 for single-unit and 1 for multi-unit). Multi-unit firms, it was assumed, could select the most efficient plants and reallocate resources accordingly. With the sample restricted to multi-unit firms, efficiency of the internal market was measured by the number of 4-digit industries in which the firm's plants were classified. Diversified firms were assumed to have greater options for resource reallocation.

For other variables, age is measured in five-year intervals based on successive census years. The amount of human capital used is measured by the average wage of the plant in each census year, while plant size is measured by total number of employees of each plant in the relevant year. Immobility of inputs is proxied by the ratio of net assets to total employment for the plant in the year of entry. Both the average wage rate (human capital variable) and net assets are in 1987 dollars, deflated with GDP deflators as shown in the Bureau of Economic Analysis (BEA)'s National Income and Product Accounts (NIPA). ${ }^{4}$ Finally, the industry average survival rate variable is measured by the

\footnotetext{
${ }^{4}$ http://www.bea.gov
} 
proportion of total number of plants in an industry in a given census year still active in the next census year.

The estimates reported in Table 2 and 3 exclude data from administrative records. This is because the latter are less reliable insofar as some variables for many plants drawn from administrative records are only guesses based on the rule of thumb procedures. Estimates, however, were also made for the entire population thereby more than doubling sample size. With four exceptions noted later, the results were largely the same.

\section{III.c. Results}

Some of the variables we proposed have, in one specification or another, appeared in previous empirical studies but not, of course, in the context of the full model we have specified. ${ }^{5}$ The results appear strongly consistent with our model and Table 2 supports substantially all the predicted relations.

The results indicate that all the coefficients of the explanatory variables are associated with low standard errors and significant at the one percent level. Most coefficients are quite stable and consistent across alternative specifications. More specifically, the results are as follows:

(a) Learning-by-doing, measured by the number of census years the plants remained in operation, shows a positive relation to the probability of survival. Learning-by-doing, however, increases the probability of plant survival at a decreasing rate as can be seen from the age fixed-effects specifications. This, as we have previously argued, is because

\footnotetext{
${ }^{5}$ For a summary of this literature see Caves (1998) and Sutton (1997).
} 
Table 2:

Probit Regressions of Plant Survival for All U.S. Manufacturing Plants, 1967-1992*

\begin{tabular}{|c|c|c|c|c|}
\hline Variables & (i) & (ii) & (iii) & (iv) \\
\hline Constant & $\begin{array}{r}-0.1154 \\
(0.0146)\end{array}$ & $\begin{array}{r}-0.1528 \\
(0.0147)\end{array}$ & $\begin{array}{r}-0.0986 \\
(0.0145)\end{array}$ & $\begin{array}{r}-0.1363 \\
(0.0146)\end{array}$ \\
\hline Age & $\begin{array}{r}0.0268 \\
(0.0004)\end{array}$ & $\begin{array}{r}0.0268 \\
(0.0004)\end{array}$ & - & \\
\hline Age2 & ' & - & $\begin{array}{r}0.2503 \\
(0.0051)\end{array}$ & $\begin{array}{r}0.2476 \\
(0.0052)\end{array}$ \\
\hline Age3 & - & - & $\begin{array}{r}0.3177 \\
(0.0066)\end{array}$ & $\begin{array}{r}0.3178 \\
(0.0068)\end{array}$ \\
\hline Age4 & - & - & $\begin{array}{r}0.3598 \\
(0.0091)\end{array}$ & $\begin{array}{r}0.3587 \\
(0.0094)\end{array}$ \\
\hline Age5 & - & - & $\begin{array}{r}0.4042 \\
(0.0143)\end{array}$ & $\begin{array}{r}0.4040 \\
(0.0147)\end{array}$ \\
\hline Tech1 & $\begin{array}{r}-0.0872 \\
(0.0050)\end{array}$ & - & $\begin{array}{r}-0.0865 \\
(0.0050)\end{array}$ & - \\
\hline Tech2 & - & $\begin{array}{r}-0.0785 \\
(0.0048)\end{array}$ & - & $\begin{array}{r}-0.0772 \\
(0.0048)\end{array}$ \\
\hline Human Capital & $\begin{array}{r}0.3891 \\
(0.0051)\end{array}$ & $\begin{array}{r}0.3945 \\
(0.0052)\end{array}$ & $\begin{array}{r}0.3876 \\
(0.0051)\end{array}$ & $\begin{array}{r}0.3929 \\
(0.0052)\end{array}$ \\
\hline Plant Size & $\begin{array}{r}0.5896 \\
(0.0055)\end{array}$ & $\begin{array}{r}0.5899 \\
(0.0057)\end{array}$ & $\begin{array}{r}0.5781 \\
(0.0056)\end{array}$ & $\begin{array}{r}0.5785 \\
(0.0057)\end{array}$ \\
\hline$(\text { Plant Size })^{2}$ & $\begin{array}{r}-0.0514 \\
(0.0009)\end{array}$ & $\begin{array}{r}-0.0516 \\
(0.0009)\end{array}$ & $\begin{array}{r}-0.0500 \\
(0.0009)\end{array}$ & $\begin{array}{r}-0.0502 \\
(0.0009)\end{array}$ \\
\hline Inputs Immobility & $\begin{array}{r}0.0909 \\
(0.0020)\end{array}$ & $\begin{array}{r}0.0876 \\
(0.0020)\end{array}$ & $\begin{array}{r}0.0906 \\
(0.0020)\end{array}$ & $\begin{array}{r}0.0874 \\
(0.0020)\end{array}$ \\
\hline Multi-unit & $\begin{array}{r}-0.0759 \\
(0.0046)\end{array}$ & $\begin{array}{r}-0.0789 \\
(0.0047)\end{array}$ & $\begin{array}{r}-0.0779 \\
(0.0046)\end{array}$ & $\begin{array}{r}-0.0810 \\
(0.0047)\end{array}$ \\
\hline Industry Survival Ratio & $\begin{array}{r}0.1220 \\
(0.0058)\end{array}$ & $\begin{array}{r}0.1804 \\
(0.0070)\end{array}$ & $\begin{array}{r}0.1224 \\
(0.0058)\end{array}$ & $\begin{array}{r}0.1802 \\
(0.0070)\end{array}$ \\
\hline
\end{tabular}

* Estimates are based on data from the LRD at the U.S. Bureau of the Census. Standard errors are in parentheses. The dependent variable is a probability of plant survival in next census year conditional on survival in current census year. The age variable is measured by five-year intervals of census years. AgeN, for $\mathrm{N}=2,3,4$ and 5, indicate age fixed effects where AgeN is one if a plant operates $\mathrm{N}$ census years and zero otherwise at a point in time. Tech1 and Tech2 indicate industry technology indexes. Each is categorical with a value of 2 for high technology industries and of 1 for low technology industries. The classification of high and low technology for the Tech1 variable is based on 3-digit SIC data on the proportion of total employment in R\&D, as shown in Hadlock, Hecker and Gannon (1991). The classification of high and low technology for the Tech2 variable is based on 4-digit SIC data on the number of innovations, as shown in Edwards and Gordon (1984). Tech2 is categorical with a value of 2 if the number of innovations in each 4digit industry is larger than or equal to the average number of innovations in all industries and of 1

otherwise. Human Capital is measured by $\log w$ where $w$ is the average wage of plant; Plant Size by $\log L$ where $L$ is total number of employees of each plant; Inputs Immobility by $\log k$ where $k$ is initial capital intensiveness (the ratio of net assets to total employment for the plant in the entry year). Multi-unit is categorical with a value of 1 for multi-unit plants and of 0 for single-unit plants. The Industry Survival Ratio is measured by the proportion of total number of plants in given census year still operating in the next census year. The sample consists of 311,436 plants. 
knowledge available to be learned is finite for a given technology. The result is also consistent with our hypothesis about the reduction in the variance of efficiencies as plants age.

(b) The probability of plant survival rises as a function of plant size but at a decreasing rate. Plants with higher estimates of efficiency invest more, but the relation does appear to attenuate as one moves to successively higher plant sizes.

(c) The faster the rate of technical change, the faster initial endowments obsolesce and, hence, the lower the probability of plant survival. This is likely to be especially true for older incumbent plants.

(d) The probability of plant survival clearly increases with the use of human capital, as previously predicted.

(e) The higher the rate of fixed capital to labor inputs, the less mobile are inputs and the higher the survival rate. The results confirm this predicted outcome.

(f) The existence of an internal market for resources as proxied by multi-unit firms is also confirmed. In multi-unit firms, reallocation appears to be facilitated and survival, thereby, reduced.

(g) The industry average survival rate is positively related to the probability of plant survival. This result is hardly surprising. It is noteworthy, however, that the results reported earlier hold after controlling for the effect of the industry average survival rate. That is, the specific variables used clearly do not simply replicate the industry average survival rate.

As noted above, data from administrative records were excluded in the reported estimates. Their inclusion greatly augments the already very large sample but reduces 
reliability and changes the results very little. More specifically, the absolute values of the coefficients for Tech1, Tech2 and plant size decline sharply. That for the multi-unit dummy rises. All the signs, however, remain unchanged. For economy of space, a table for these estimates is not shown but is available on request to the authors.

In the above empirical specifications, we did not include a measure of the firm's total commitment to a given activity as an alternative to plant size, nor a measure of product diversification (reflecting the efficiency of the internal market), because these variables overlap plant size and the multi-unit dummy, respectively. In order to test the effects of these variables, we therefore restricted our sample to multi-unit firms. This still left us a very large non-balanced panel of 109,364 plants. For the multi-unit universe, inclusion of administrative records changes the sample negligibly. Hence, the estimates remain virtually the same. Therefore, we report only the estimates excluding administrative records.

We next tested the same model as for Table 2 but replaced plant size with the firm size variable where firm size was measured by total employment of the firm in the 4-digit SIC industry of the relevant plant. Thus firm size measures the scale of the firm's total activity in the industry of the plant. Diversification replaced the multi-unit dummy where diversification was measured by the number of primary 4-digit industries in which the plants of the firm were classified. Thus diversification measures the range of industries in which the owning firms had activities. Each of these two variables was measured for every census year in the period examined. All other variables are defined as for Table 2. Table 3 shows the new results. The results strongly confirm those already shown in Table 2. The coefficients of the explanatory variables are significant at the one percent level 
Table 3:

Probit Regressions of Plant Survival

for Multi-unit U.S. Manufacturing Plants, 1967-1992*

\begin{tabular}{|c|c|c|c|c|}
\hline Variables & (i) & (ii) & (iii) & (iv) \\
\hline Constant & $\begin{array}{r}-0.2991 \\
(0.0259)\end{array}$ & $\begin{array}{r}-0.3599 \\
(0.0263)\end{array}$ & $\begin{array}{r}-0.2911 \\
(0.0259)\end{array}$ & $\begin{array}{r}-0.3515 \\
(0.0263)\end{array}$ \\
\hline Age & $\begin{array}{r}0.0195 \\
(0.0006)\end{array}$ & $\begin{array}{r}0.0192 \\
(0.0006)\end{array}$ & - & - \\
\hline Age2 & - & - & $\begin{array}{r}0.1667 \\
(0.0080)\end{array}$ & $\begin{array}{r}0.1630 \\
(0.0083)\end{array}$ \\
\hline Age3 & - & - & $\begin{array}{r}0.2075 \\
(0.0099)\end{array}$ & $\begin{array}{r}0.2039 \\
(0.0103)\end{array}$ \\
\hline Age4 & - & - & $\begin{array}{r}0.2779 \\
(0.0129)\end{array}$ & $\begin{array}{r}0.2739 \\
(0.0133)\end{array}$ \\
\hline Age5 & - & - & $\begin{array}{r}0.3678 \\
(0.0197)\end{array}$ & $\begin{array}{r}0.3671 \\
(0.0203)\end{array}$ \\
\hline Tech1 & $\begin{array}{r}-0.0704 \\
(0.0075)\end{array}$ & - & $\begin{array}{r}-0.0704 \\
(0.0075)\end{array}$ & - \\
\hline Tech2 & - & $\begin{array}{r}-0.0291 \\
(0.0074)\end{array}$ & - & $\begin{array}{r}-0.0290 \\
(0.0074)\end{array}$ \\
\hline Human Capital & $\begin{array}{r}0.0847 \\
(0.0088)\end{array}$ & $\begin{array}{r}0.0864 \\
(0.0091)\end{array}$ & $\begin{array}{r}0.0860 \\
(0.0088)\end{array}$ & $\begin{array}{r}0.0876 \\
(0.0091)\end{array}$ \\
\hline Firm Size & $\begin{array}{r}0.3221 \\
(0.0074)\end{array}$ & $\begin{array}{r}0.3209 \\
(0.0076)\end{array}$ & $\begin{array}{r}0.3201 \\
(0.0074)\end{array}$ & $\begin{array}{r}0.3190 \\
(0.0076)\end{array}$ \\
\hline$(\text { Firm Size })^{2}$ & $\begin{array}{r}-0.0198 \\
(0.0007)\end{array}$ & $\begin{array}{r}-0.0197 \\
(0.0008)\end{array}$ & $\begin{array}{r}-0.0196 \\
(0.0007)\end{array}$ & $\begin{array}{r}-0.0195 \\
(0.0008)\end{array}$ \\
\hline Inputs Immobility & $\begin{array}{r}0.1032 \\
(0.0029)\end{array}$ & $\begin{array}{r}0.0987 \\
(0.0030)\end{array}$ & $\begin{array}{r}0.1030 \\
(0.0030)\end{array}$ & $\begin{array}{r}0.0986 \\
(0.0030)\end{array}$ \\
\hline Diversification & $\begin{array}{r}-0.0017 \\
(0.0004)\end{array}$ & $\begin{array}{r}-0.0020 \\
(0.0004)\end{array}$ & $\begin{array}{r}-0.0017 \\
(0.0004)\end{array}$ & $\begin{array}{r}-0.0020 \\
(0.0004)\end{array}$ \\
\hline Industry Survival Ratio & $\begin{array}{r}0.0742 \\
(0.0084)\end{array}$ & $\begin{array}{r}0.0911 \\
(0.0096)\end{array}$ & $\begin{array}{r}0.0748 \\
(0.0084)\end{array}$ & $\begin{array}{r}0.0914 \\
(0.0096)\end{array}$ \\
\hline
\end{tabular}

* Estimates are based on data from the LRD at the U.S. Bureau of the Census. Standard errors are in parentheses. Firm Size is measured by $\log L_{f}$ where $L_{f}$ is total number of employees of the firm limited to the specific 4-digit SIC industry. Diversification is the number of primary 4-digit industries in which the firm's plants operated. All other variables are as defined in Table 2. The sample consists of 109,364 plants. 
and are quite stable and consistent across alternative specifications.

The new conclusions are:

(a) Firm size limited to the specific 4-digit SIC industry of the plant shows a positive relation to the probability of plant survival, but once again the probability of plant survival rises at a decreasing rate with increments to size.

(b) Firm diversification is negatively associated with survival. This implies that the selection effect on plant survival dominates the portfolio effect previously discussed. It contradicts the earlier result of Agarwal and Gort (2002) which showed a positive effect of diversification on survival. However, the Agarwal and Gort study dealt with firm rather than plant survival. It is entirely plausible that the portfolio effect would dominate in determining firm survival while selection of activities and opportunities for internal reallocation of resources dominate for plants. The Agarwal and Gort result, moreover, was based on a measure of diversification that distinguished between firms entering a new activity with ongoing operations in other markets from completely new and, hence, single activity firms. The latter are particularly vulnerable to bankruptcy and this may contribute to explaining the result.

Our model could, in principle, have been estimated with the inclusion of investment. The latter would be a partially endogenous variable to the extent it is a function of learning-by-doing, initial endowments and technical change (as explained earlier). Data limitations, however, precluded two-stage estimation. The restriction of information to census years and the absence of annual data rendered this approach not feasible. 


\section{Conclusions}

There is a high rate of attrition of new plants in U.S. manufacturing industries with only about a fifth surviving after twenty years. The high rate of exit from production warrants close study of the causes and effects of the phenomenon. One question with both research and policy implications is whether depreciation rates for capital goods derived from data for surviving plants are not downward biased when applied to the universe of plants.

In explaining variations in the probability of survival, a model with three vectors of variables was developed. The first explains the rising survival with age of plants, and the association of survival with plant size (and implicitly plant growth), as a consequence of learning by firms about the relative efficiencies of their own plants. The second explains changes in endowments and, hence, survival as a function of learning-by-doing and obsolescence, with the latter a function of the rate of technical change. And the third focuses on the opportunity cost of resources which, in turn, depends on the mobility of inputs and existence of a market internal to the firm through which resources are reallocated.

The model is tested using maximum-likelihood probit analysis. The specific variables that explain survival are plant age and plant size, both of which have a nonlinear relation to survival, the rate of technical change in the plants' primary industry and the quantity of human capital the plant employs. In addition, of relevance is the immobility of inputs as reflected in the relative importance of fixed capital, and the existence of opportunities for internal reallocation of resources captured by the existence of (a) other plants, and (b) other industrial activities, within the firm. 


\section{REFERENCES}

Agarwal, Rajshree, and Michael Gort, "Firm and Product Life Cycles and Firm Survival," American Economic Review (forthcoming. 2002).

Audretsch, David B., "Innovation, Growth and Survival," International Journal of Industrial Organization 13 (Dec. 1995), 441-458.

Baldwin, John R., and Paul K. Gorecki, "Firm Entry and Exit in the Canadian Manufacturing Sector, 1970-1982," Canadian Journal of Economics 14 (May 1991), 300-323.

Caves, Richard E., "Industrial Organization and New Findings on the Turnover and Mobility of Firms,” Journal of Economic Literature 36 (Dec. 1998), 1947-1982.

Doms, Mark, Timothy Dunne, and Mark J. Roberts, "The Role of Technology Use in the Survival and Growth of Manufacturing Plants," International Journal of Industrial Organization 13 (Dec. 1995), 523-542.

Dunne, Timothy, Mark J. Roberts, and Larry Samuelson, "The Growth and Failure of U.S. Manufacturing Plants," Quarterly Journal of Economics 104 (Nov. 1989), 671-698.

Dunne, Timothy, Mark J. Roberts, and Larry Samuelson, "Patterns of Firm Entry and Exit in the U.S. Manufacturing Industries," Rand Journal of Economics 19 (Winter 1988), 495-515.

Edwards, Keith L., and Theodore J. Gordon, "Characterization of Innovation Introduced on the U.S. Market in 1982," (The Futures Group, 1984), prepared for the U.S. Small Business Administration.

Evans, David S., “The Relationship between Firm Growth, Size and Age: Estimates from 
100 Manufacturing Industries," Journal of Industrial Economics 35 (Jun. 1987a), $567-581$.

Evans, David S., "Tests of Alternative Theories of Firm Growth," Journal of Political Economy 95 (Aug. 1987b) 657-674.

Gort, Michael, and Seong-Hoon Lee, "The Life Cycles of Industrial Plants," Center for Economic Studies, U.S. Bureau of the Census, Working Paper (2001).

Hadlock, Paul, Daniel Hecker, and Joseph Gannon, "High Technology Employment: Another View," Monthly Labor Review 114 (Jul. 1991), 26-30.

Jovanovic, Boyan, "Selection and Evolution of Industry," Econometrica 50 (May 1982), 649-670.

Mata, Jose, Pedro Portugal and Paulo Guimaraes, "The Survival of New Plants: Start-up Conditions and Post-entry Evolution," International Journal of Industrial Organization 13 (Dec. 1995), 459-482.

Schwalbach, Joachim, "Entry, Exit, Concentration and Market Contestability," in Entry and Market Contestability: An International Comparison, eds. Geroski, P. A., and Schwalbach, J., (Cambridge: Blackwell, Ch 7, 1991), 121-142.

Sutton, John, “Gibrat’s Legacy,” Journal of Economic Literature 35 (Mar. 1997), 40-59. Wagner, Joachim, “The Post-Entry Performance of New Small Firms In German Manufacturing Industries," Journal of Industrial Economics 62 (Jun. 1994), 141154. 